\title{
Assessment of various efficacy outcomes using ERIVANCE-like criteria in patients with locally advanced basal cell carcinoma receiving sonidegib: results from a preplanned sensitivity analysis
}

Ralf Gutzmer ${ }^{1 *}$, Caroline Robert ${ }^{2}$, Carmen Loquai ${ }^{3}$, Dirk Schadendorf ${ }^{4,5}$, Nicholas Squittieri ${ }^{6}$, Ramon Arntz ${ }^{7}$, Serena Martelli ${ }^{7}$ and Reinhard Dummer ${ }^{8}$

\begin{abstract}
Background: The BOLT study for sonidegib, a Hedgehog pathway inhibitor $(\mathrm{HH})$ approved for patients with locally advanced basal cell carcinoma (laBCC) not amenable to curative surgery or radiotherapy, used modified Response Evaluation Criteria in Solid Tumors (mRECIST) for laBCC tumor evaluation. The ERIVANCE study for vismodegib, another $\mathrm{HHI}$, used a composite RECIST endpoint of $\geq 30 \%$ reduction in externally visible tumor or radiographic dimension, or complete ulceration resolution. This preplanned sensitivity BOLT analysis evaluated efficacy outcomes using ERIVANCE-like criteria in patients with laBCC who received sonidegib $200 \mathrm{mg}$ once daily.

Methods: This phase 2, double-blind study randomized patients 1:2 to sonidegib 200:800 mg daily, respectively. Key endpoints included objective response rate (ORR), duration of response (DOR), complete response (CR), partial response (PR), stable disease (SD), and progressive disease (PD). laBCC tumors were assessed by both mRECIST and ERIVANCE-like criteria. Per mRECIST, an overall response of CR was based on negative histology; photographic assessment of CR, PR (scar/fibrosis only), SD (scar/fibrosis only), or not available (NA); and a magnetic resonance imaging response of $C R$ or NA. An overall response of CR was primarily based on negative histology using ERIVAN CE-like criteria.

Results: Per mRECIST criteria, ORR (95\% confidence interval [CI]) by central and investigator review for patients with laBCC $(n=66)$ was $56.1 \%(43.3-68.3 \%)$ and $71.2 \%(58.7-81.7 \%)$, respectively. CR per central review was achieved in 3 (4.5\%) patients and PR, SD, and PD occurred in 34 (51.5\%), 23 (34.8\%), and 1 (1.5\%) patient, respectively. Median (95\% Cl) DOR was 26.1 months (not estimable [NE]).

Using ERIVANCE-like criteria, efficacy outcomes per central and investigator review were higher, with an ORR (95\% Cl) of $60.6 \%(47.8-72.4 \%)$ and $74.2 \%(62.0-84.2 \%)$, respectively. CR per central review was reached in $14(21.2 \%)$ patients and PR, SD, and PD occurred in 26 (39.4\%), 20 (30.3\%), and 1 (1.5\%) patient, respectively. DOR was
\end{abstract}

* Correspondence: ralf.gutzmer@ruhr-uni-bochum.de

'Department Dermatology, Johannes Wesling Hospital Minden, Ruhr-University Bochum, Hans-Nolte-Str. 1, 32429 Minden, Germany

Full list of author information is available at the end of the article

(c) The Author(s). 2021 Open Access This article is licensed under a Creative Commons Attribution 4.0 International License, which permits use, sharing, adaptation, distribution and reproduction in any medium or format, as long as you give appropriate credit to the original author(s) and the source, provide a link to the Creative Commons licence, and indicate if changes were made. The images or other third party material in this article are included in the article's Creative Commons licence, unless indicated otherwise in a credit line to the material. If material is not included in the article's Creative Commons licence and your intended use is not permitted by statutory regulation or exceeds the permitted use, you will need to obtain permission directly from the copyright holder. To view a copy of this licence, visit http://creativecommons.org/licenses/by/4.0/ The Creative Commons Public Domain Dedication waiver (http://creativecommons.org/publicdomain/zero/1.0/) applies to the data made available in this article, unless otherwise stated in a credit line to the data. 
unchanged with a median (95\% Cl) of 26.1 months (NE).

Conclusions: Overall, applying ERIVANCE-like criteria to patients with laBCC receiving sonidegib $200 \mathrm{mg}$ daily yielded higher response rates vs MRECIST criteria.

Trial registration: BOLT registration: ClinicalTrials.gov (NCT01327053) on March 30, 2011.

Keywords: Basal cell carcinoma, Hedgehog pathway inhibitor, Sonidegib, mRECIST, Tumor outcome

\section{Background}

Basal cell carcinoma (BCC) is the most common cancer worldwide and constitutes $80 \%$ of the 3.5 million cases of nonmelanoma skin cancer diagnosed each year [1-3]. In most cases of $\mathrm{BCC}$, the American Academy of Dermatology and the European consensus-based interdisciplinary guidelines recommend surgery as the standard treatment, which has an excellent prognosis [4-6]. However, in cases of advanced $\mathrm{BCC}$, treatment options are limited due to significant tissue invasion and associated morbidity $[2,7]$. Advanced BCC can be characterized as either locally advanced BCC (laBCC), in which tumors are substantially enlarged and locally destructive to the point that surgery is no longer feasible or surgical resection would result in considerable deformity; or metastatic BCC (mBCC), which is associated with high morbidity and mortality [7]. In an analysis at a tertiary referral center, the prevalence of complicated BCC cases was estimated to be $7.2 \%$ of all BCC cases; these patients generally also had greater variations of $\mathrm{BCC}$ histologic subtypes compared with patients with non-advanced cases of BCC [8]. Moreover, patients with advanced $\mathrm{BCC}$ were more likely to have histologically aggressive subtypes of BCC compared with patients with nonadvanced $\mathrm{BCC}$, which increases the risk of tumor recurrence due to a greater likelihood of incomplete primary excision $[8,9]$. Consequently, patients with advanced BCC may have complications and require extensive and prolonged treatment.

Development of $\mathrm{BCC}$ is associated with upregulation of the Hedgehog signaling pathway, with somatic mutations of this pathway present in most cases of BCC $[1,7$, 10]. Consequently, in patients with advanced BCC, when surgery and radiotherapy are contraindicated or pose a significant management challenge, such as substantial posttreatment deformity, systemic Hedgehog pathway inhibitors (HHIs) are recommended [4, 6, 7]. Two HHIs are currently approved for the treatment of advanced BCC: sonidegib (Odomzo ${ }^{\circ}$ S Sun Pharmaceutical Industries, Inc.; Cranbury, NJ) and vismodegib (Erivedge ${ }^{\circ}$; Genentech, Inc.; San Francisco, CA), which both target selectively Smoothened, a Hedgehog pathway protein $[11,12]$. Sonidegib is approved in the US, EU, Switzerland, and Australia for the treatment of adult patients with laBCC who are not amenable to curative surgery or radiation therapy [11, 13-15]. Additionally, sonidegib is approved to treat $\mathrm{mBCC}$ in Switzerland and Australia [14, 15]. Vismodegib is approved in the US for the treatment of adults with $\mathrm{mBCC}$ or laBCC that has recurred after surgery, or for those who are not surgical or radiotherapy candidates, and is approved in the EU, Switzerland, and Australia for adults with laBCC or $\mathrm{mBCC}$ when surgery or radiotherapy is inappropriate $[12,16-18]$.

In the pivotal 42-month phase 2 BOLT (Basal Cell Carcinoma Outcomes with LDE225 [sonidegib] Treatment) study (NCT01327053) evaluating efficacy and safety in patients with laBCC and $\mathrm{mBCC}$, sonidegib 200 mg once daily (QD) demonstrated robust efficacy and manageable toxicity [19-22]. Tumor assessments for patients with laBCC were performed by a central review committee and investigators using modified Response Evaluation Criteria in Solid Tumors (mRECIST). These modified criteria were used in place of RECIST v1.1 criteria to address the challenges in determining tumor response in patients with laBCC due to potential morphological changes following treatment, including ulceration, cyst formation, fibrosis, and poorly defined lesions [22]. In contrast, in the phase 2, single-arm, 2cohort ERIVANCE study evaluating efficacy and safety of vismodegib, tumor response in patients with laBCC was assessed using a composite endpoint integrating $\mathrm{a} \geq$ $30 \%$ reduction into the externally visible or radiographic dimension of the tumor (RECIST criteria) or complete ulceration resolution if present at baseline [23, 24].

Overall, both the mRECIST criteria used in the BOLT study and the composite RECIST criteria used in the ERIVANCE study incorporate magnetic resonance imaging (MRI) per RECIST v1.1, color photography per World Health Organization (WHO) guidelines, and histology for laBCC tumor assessment. However, the algorithm determining overall response differs between the two criteria used, and mRECIST utilizes more stringent methods of tumor assessment to calculate a composite overall response, resulting in efficacy outcomes for which the response is lower for mRECIST compared with RECIST v1.1 [21]. In the absence of head-to-head clinical studies comparing sonidegib and vismodegib, a preplanned sensitivity analysis in the BOLT trial, which applied ERIVANCE-like criteria to laBCC tumor 
outcomes, was performed. Here, we present the results of this sensitivity analysis evaluating the subset population of patients with laBCC who received the approved $200 \mathrm{mg}$ QD dose of sonidegib.

\section{Methods}

\section{Study design}

BOLT was a multicenter, double-blind, randomized, phase 2 international clinical study, and enrolled patients were randomized 1:2 to sonidegib 200 or $800 \mathrm{mg}$ QD. Patient baseline clinical characteristics and study design were previously described [19-22]. Patients eligible for inclusion in the study were $\geq 18$ years of age and had either histologically confirmed laBCC that was not amenable to curative surgery, radiotherapy, or localized therapies, or histologically confirmed $\mathrm{mBCC}$. Patients with laBCC were required to have measurable disease, defined as $\geq 1$ lesion that could be accurately measured in at least one dimension as $\geq 10$ $\mathrm{mm}$ with an MRI scan or with annotated color photographs. Patients additionally needed a WHO performance status of $\leq 2$ and sufficient bone marrow and liver and renal function. At screening, punch tumor biopsies within 21 days prior to the initiation of study treatment were required for all patients with accessible laBCC tumors. For patients without accessible laBCC tumors, such as tumors in difficult anatomical locations, collection of an archival tumor tissue sample was required at screening.

The primary endpoint was objective response rate (ORR) per central review, defined as the percentage of patients with a best overall response of complete response (CR) or partial response (PR) based on consecutive evaluations $\geq 4$ weeks apart. Secondary assessments included $\mathrm{CR}$, $\mathrm{PR}$, stable disease (SD), progressive disease (PD), and duration of response (DOR). laBCC tumors were assessed utilizing mRECIST criteria integrating MRI, color photography, and histological tumor tissue evaluation and then analyzed in a preplanned sensitivity analysis with criteria similar to that used in the ERIVANCE study.

Per mRECIST criteria, an overall composite response of $\mathrm{CR}$ was based on the following measures: negative histology for multiple punch biopsies; photographic assessment of CR, PR (scar/fibrosis only), SD (scar/fibrosis only), or not available (NA); and an MRI response of either CR or NA (Table 1). A minimum of two $3-4 \mathrm{~mm}$ punch biopsies were required per patient, although the specific number of biopsy samples taken depended on the size of the original target tumor with approximately one $3-4 \mathrm{~mm}$ sample taken from every $4-\mathrm{cm}^{2}$ area of tumor tissue. PR per mRECIST was determined by the following: negative histology, CR, PR (scar/fibrosis only), or SD (scar/fibrosis only) per photographic assessment, and an MRI response of either PR or $\mathrm{SD}$; negative histology, PR per photographic assessment, and MRI response of CR, PR, SD, or NA; or, alternatively, negative histology, NA per photographic assessment, and an MRI response of PR. Per the ERIVANCE-like criteria, $\mathrm{CR}$ was based on negative histology and CR, PR, SD, or NA for MRI assessment and photographic evaluation. In addition, PR per ERIVANCE-like criteria was defined as histological assessment of positive or unknown, SD or SD (scar/fibrosis only) per photographic evaluation, and an MRI response of CR or PR. This ERIVANCE-like criteria used to define PR were the same as the mRECIST-defining criteria for SD. Consequently, the criteria used to define $\mathrm{CR}$ per ERIVANCE-like criteria were often the same as those used to define PR per mRECIST.

Written informed consent was obtained from all patients prior to the start of the study. The study protocol and all amendments were approved by the independent ethics committee or institutional review board for each center (Supplementary Table 1). This study was carried out in accordance with the ethical principles of the Declaration of Helsinki.

\section{Assessments}

All patients followed the same treatment protocol of an oral dose of sonidegib 200 or $800 \mathrm{mg}$ QD until PD (determined by radiological scans or clinical photography per central review), intolerable toxicity, withdrawal of consent, study discontinuation, or death. Only data for patients with laBCC receiving the approved $200 \mathrm{mg}$ QD dose are reported in this analysis. Following baseline tumor assessments at screening, additional tumor response evaluations were performed at weeks 5,9 , and 17 ( \pm 3 days) and subsequently every 8 weeks ( \pm 3 days) during the first year, followed by every 12 weeks ( \pm 3 days) thereafter until confirmation of PD, start of a new antineoplastic therapy, loss to follow-up, or end of treatment.

Safety assessments involved monitoring and recording adverse events (AEs), including serious AEs, in addition to regular monitoring of hematology, clinical chemistry laboratory, and electrocardiogram abnormalities, as well as checking vital signs and physical condition.

\section{Statistical analyses}

All statistical methods were previously described in detail [19-22]. Treatment with sonidegib was considered efficacious when the ORR of any treatment arm at the end of the study was $\geq 30 \%$. Primary and secondary endpoints were estimated with $95 \%$ confidence intervals (CIs), with a lower bound of the $95 \%$ CI exceeding $20 \%$ considered clinically meaningful. ORR was calculated using point estimates and $95 \% \mathrm{CI}$, while medians and 95\% CIs were derived using Kaplan-Meier methodology for DOR evaluations.

\section{Results}

Baseline patient characteristics

Among the 230 patients enrolled in BOLT, 66 patients with laBCC were randomized to sonidegib $200 \mathrm{mg}$. 
Patient demographics and baseline disease characteristics were reported previously (Supplementary Table 2) [22]. Of the patients with laBCC receiving sonidegib 200 mg QD, 37 (46.8\%) had aggressive and 29 (36.7\%) had nonaggressive subtypes. Overall, median duration of exposure to sonidegib was 11 months for all patients (laBCC and $\mathrm{mBCC}$ combined) receiving sonidegib 200 $\mathrm{mg} ; 92.4 \%$ of all patients in the sonidegib $200 \mathrm{mg}$ arm discontinued treatment by the end of the study. The most common reasons for study discontinuation for all patients in the sonidegib $200 \mathrm{mg}$ arm were PD (36.7\%), AEs (29.1\%), physician decision (12.7\%), patient decision (10.1\%), loss to follow-up (2.5\%), and death (1.3\%).

\section{Per central review}

\section{Best overall response using ERIVANCE-like vs mRECIST criteria}

Through 42 months of treatment with sonidegib $200 \mathrm{mg}$ QD, ORR (95\% CI) for patients with laBCC was $56.1 \%$ (43.3-68.3\%) per mRECIST (Table 2). CR was achieved in $3(4.5 \%)$ patients, while PR occurred in 34 (51.5\%) patients per central review. Comparatively, when using ERIVANCE-like criteria, ORR (95\% CI) per central review was $60.6 \%(47.8-72.4 \%)$ for patients with laBCC receiving sonidegib $200 \mathrm{mg}$ QD. Similarly, CR was achieved in 14 (21.2\%) patients and PR occurred in 26 (39.4\%) patients.

When tumor response was analyzed by histologic subtype, ORR $(95 \% \mathrm{CI})$ per mRECIST for patients with aggressive vs nonaggressive subtypes of laBCC was $59.5 \%$ (42.1-75.2\%) vs $51.7 \%$ (32.5-70.6\%), respectively. CR per mRECIST was achieved in $2(5.4 \%)$ patients and 1 (3.4\%) patient with aggressive and nonaggressive subtypes, respectively. In contrast, ORR $(95 \% \mathrm{CI})$ per ERIVANCElike criteria for patients with aggressive vs nonaggressive histologic subtypes was $64.9 \%(47.5-79.8 \%)$ vs $55.2 \%$ (35.7-73.6\%), respectively. Moreover, CR per ERIVAN CE-like criteria was achieved in $8(21.6 \%)$ patients and 6 (20.7\%) patients with aggressive and nonaggressive subtypes, respectively.

Table 1 Composite overall response in laBCC determined by ERIVANCE-like vs mRECIST criteria

\begin{tabular}{|c|c|c|c|c|}
\hline \multirow[t]{2}{*}{$\mathrm{MRI}^{\mathrm{a}}$} & \multirow[t]{2}{*}{ Photograph $^{\text {b }}$} & \multirow[t]{2}{*}{ Histologyc } & \multicolumn{2}{|c|}{ Composite overall response } \\
\hline & & & $\overline{m R E C I S T} T^{d, e}$ & ERIVANCE-like criteria \\
\hline \multirow[t]{3}{*}{$\overline{C R}$} & $C R$ & Negative & $C R^{C}$ & $C R$ \\
\hline & PR (scar/fibrosis only) or SD (scar/fibrosis only) & Negative & & \\
\hline & NA & Negative & & \\
\hline \multirow[t]{2}{*}{ NA } & $C R$ & Negative & $C R^{c}$ & $C R$ \\
\hline & PR (scar/fibrosis only) or SD (scar/fibrosis only) & Negative & & \\
\hline \multirow[t]{2}{*}{ PR } & $C R$ & Negative & PR & $C R$ \\
\hline & PR (scar/fibrosis only) or SD (scar/fibrosis only) & Negative & & \\
\hline \multirow[t]{2}{*}{ SD } & $C R$ & Negative & $P R$ & $C R$ \\
\hline & PR (scar/fibrosis only) or SD (scar/fibrosis only) & Negative & & \\
\hline$C R$ & PR & Negative & $P R$ & $C R$ \\
\hline \multicolumn{5}{|l|}{ PR } \\
\hline \multicolumn{5}{|l|}{ SD } \\
\hline \multicolumn{5}{|l|}{ NA } \\
\hline$C R$ & SD & Negative & SD & $C R$ \\
\hline \multicolumn{5}{|l|}{ PR } \\
\hline PR & NA & Negative & $P R$ & $C R$ \\
\hline \multirow[t]{2}{*}{$C R$} & SD & Positive or unknown & SD & PR \\
\hline & SD (scarring/fibrosis only) & & & \\
\hline \multirow[t]{2}{*}{$P R$} & SD & Positive or unknown & SD & $P R$ \\
\hline & SD (scarring/fibrosis only) & & & \\
\hline
\end{tabular}

${ }^{a}$ Measurability per central review per RECIST v1.1 [23]

${ }^{\mathrm{b}} \mathrm{PR} \geq 50 \%$ reduction in the sum of perpendicular products; PD $\geq 25 \%$ increase in the sum of products per WHO criteria [25]

${ }^{\mathrm{C}} \mathrm{Confirmed} \mathrm{CRs}$ required multiple punch biopsy samples per lesion

${ }^{\mathrm{d}}$ An independent review committee reevaluated all assessments for the laBCC cohort to determine a composite response

'Since posttreatment ulceration, cyst formation, and scarring/fibrosis may be considered treatment effects and are not necessarily indicative of disease

progression in laBCC, "scarring/fibrosis only" was allowed per mRECIST criteria, given that the other measures such as histology and MRI also showed no signs of disease progression

$C R$ complete response, IaBCC locally advanced basal cell carcinoma, $m R E C I S T$ modified RECIST, MRI magnetic resonance imaging, NA not available, $P D$ progressive disease, $P R$ partial response, RECIST Response Evaluation Criteria in Solid Tumors, SD stable disease, WHO World Health Organization 
Table 2 Best overall response in patients with laBCC receiving sonidegib 200 mg daily by central review

\begin{tabular}{|c|c|c|}
\hline & mRECIST criteria & ERIVANCE-like criteria \\
\hline laBCC, all & $n=66$ & $n=66$ \\
\hline ORR, \% (95\% Cl) & $56.1(43.3-68.3)$ & $60.6(47.8-72.4)$ \\
\hline CR, \% (95\% Cl) & $4.5(0.9-12.7)$ & $21.2(12.1-33.0)$ \\
\hline $\mathrm{PR}, \%$ & 51.5 & 39.4 \\
\hline $\mathrm{SD}, \%$ & 34.8 & 30.3 \\
\hline$P D, \%$ & 1.5 & 1.5 \\
\hline Unknown, \% & 7.6 & 7.6 \\
\hline laBCC, aggressive histology ${ }^{a}$ & $n=37$ & $n=37$ \\
\hline ORR, \% (95\% Cl) & $59.5(42.1-75.2)$ & $64.9(47.5-79.8)$ \\
\hline CR, \% $(95 \% \mathrm{Cl})$ & $5.4(0.7-18.2)$ & $21.6(9.8-38.2)$ \\
\hline $\mathrm{PR}, \%$ & 54.1 & 43.2 \\
\hline $\mathrm{SD}, \%$ & 32.4 & 27.0 \\
\hline$P D, \%$ & 2.7 & 2.7 \\
\hline Unknown, \% & 5.4 & 5.4 \\
\hline laBCC, nonaggressive histology ${ }^{b}$ & $n=29$ & $n=29$ \\
\hline ORR, \% (95\% Cl) & $51.7(32.5-70.6)$ & $55.2(35.7-73.6)$ \\
\hline CR, \% (95\% Cl) & $3.4(0.1-17.8)$ & $20.7(8.0-39.7)$ \\
\hline $\mathrm{PR}, \%$ & 48.3 & 34.5 \\
\hline $\mathrm{SD}, \%$ & 37.9 & 34.5 \\
\hline$P D, \%$ & 0 & 0 \\
\hline Unknown, \% & 10.3 & 10.3 \\
\hline
\end{tabular}

${ }^{a}$ Includes basosquamous, micronodular infiltrative, multifocal, and sclerosing histological subtypes

${ }^{b}$ Includes nodular and superficial histological subtypes

$C l$ confidence interval, $C R$ complete response, laBCC locally advanced basal cell carcinoma, mRECIST modified RECIST, ORR overall response rate, PD progressive disease, $P R$ partial response, RECIST Response Evaluation Criteria in Solid Tumors, SD stable disease

\section{Duration of response using ERIVANCE-like vs mRECIST criteria}

In patients with laBCC receiving sonidegib $200 \mathrm{mg}$, median (95\% CI) DOR was 26.1 months (not estimable [NE]) with event-free probability estimates (95\% CI) for 12 months of $64.9 \%$ (42.3-80.4\%), per mRECIST (Table 3). When DOR was assessed using ERIVANCE-like criteria, it was unchanged with a median DOR (95\% CI) of 26.1 months (NE). However, event-free probability estimates (95\% CI) were higher for 12 months (69.2\% [46.5-83.8\%]).

Analyses of event-free probability estimates by histologic subtype demonstrated overall higher estimates for 6, 9, and 12 months per ERIVANCE-like criteria vs mRECIST for patients with nonaggressive subtypes of laBCC $(92.3 \% \quad$ [56.6-98.9\%] vs $91.7 \%$ [53.9-98.8\%], $84.6 \%$ [51.2-95.9\%] vs $75.0 \%$ [40.8$91.2 \%]$, and $70.5 \%$ [30.6-90.2\%] vs $75.0 \%$ [40.891.2\%], respectively. Similarly, event-free probability estimates were greater for patients with aggressive subtypes per ERIVANCE-like criteria vs mRECIST with 6-, 9-, and 12-month estimates of $89.9 \%$ (65.3$97.4 \%)$ vs $82.9 \%$ (55.7-94.2\%), $83.5 \%$ (56.7-94.5\%) vs $76.0 \%(47.6 \%-90.3)$, and $67.5 \%(37.3-85.5 \%)$ vs $57.9 \%$ $(27.6-79.3 \%)$, respectively.

Table 3 Duration of response in patients with laBCC receiving sonidegib $200 \mathrm{mg}$ daily by central review

\begin{tabular}{|c|c|c|}
\hline & mRECIST criteria & ERIVANCE-like criteria \\
\hline DOR, median, months, (95\% Cl) & 26.1 (NE) & 26.1 (NE) \\
\hline \multicolumn{3}{|c|}{ Event-free probability estimate, \%, $(95 \% \mathrm{Cl})$} \\
\hline 6 months & $86.4(67.7-94.7)$ & $90.8(74.1-96.9)$ \\
\hline 9 months & $74.9(54.4-87.2)$ & $83.8(65.3-93.0)$ \\
\hline 12 months & $64.9(42.3-80.4)$ & $69.2(46.5-83.8)$ \\
\hline
\end{tabular}

Cl confidence interval, DOR duration of response, IaBCC locally advanced basal cell carcinoma, mRECIST modified RECIST, NE not estimable, RECIST Response Evaluation Criteria in Solid Tumors 
Per investigator review

Best overall response using ERIVANCE-like vs MRECIST criteria

Analyses of tumor response by investigator review showed greater responses per ERIVANCE-like criteria vs mRECIST for patients with laBCC with an ORR (95\% CI) of $74.2 \%$ (62.0-84.2\%) vs 71.2\% (58.7-81.7\%). Per mRECIST, CR was achieved in $6(9.1 \%)$ patients, while PR occurred in 41 (62.1\%) patients per investigator review (Table 4). In contrast, CR was achieved in 19 (28.8\%) patients and PR occurred in 30 (45.5\%) patients using ERIVANCE-like criteria.

When tumor response was analyzed by histologic subtype, ORR (95\% CI) per mRECIST for patients with aggressive vs nonaggressive subtypes of laBCC was $70.3 \%$ (53.0$84.1 \%)$ vs $72.4 \%$ (52.8-87.3\%), respectively. Conversely, ORR (95\% CI) using ERIVANCE-like criteria for patients with aggressive vs nonaggressive subtypes of laBCC was $75.7 \%$ (58.8-88.2\%) vs 72.4\% (52.8-87.3\%), respectively.

\section{Duration of response using ERIVANCE-like vs mRECIST criteria}

Median DOR (95\% CI) using mRECIST criteria per investigator review for patients with laBCC receiving sonidegib $200 \mathrm{mg}$ QD was 15.7 (12.0-20.2) months compared with a median DOR of 18.2 (12.9-24.0) months using ERIVANCE-like criteria. Event-free probability estimates using mRECIST criteria for 6, 9, and 12 months were $89.8 \%$ (74.8-96.1\%), 80.7\% (63.5-90.4\%), and 71.4\% (53.1-83.6\%), respectively. In contrast, event-free probability estimates using ERIVANCE-like criteria were higher for 6, 9, and 12 months at 93.2\% (75.5-98.3\%), $89.2 \% \quad(69.9-96.4 \%)$, and $84.7 \% \quad(63.9-94.0 \%)$, respectively.

\section{Safety}

As previously described, the majority of AEs were manageable and consistent with prior assessments at the final 42-month BOLT analysis [19]. In patients receiving sonidegib $200 \mathrm{mg}$ QD, AEs were predominantly Grade 1 or 2 , and the incidence of serious AEs considered related to treatment was observed in $4(5.1 \%)$ patients. AEs reported in $\geq 30 \%$ of patients receiving sonidegib $200 \mathrm{mg}$ QD were muscle spasms (54.4\%), alopecia (49.4\%), dysgeusia $(44.3 \%)$, nausea $(39.2 \%)$, fatigue $(32.9 \%)$, diarrhea (31.6\%), elevated blood creatine phosphokinase (30.4\%), and weight loss (30.4\%).

Table 4 Best overall response in patients with laBCC receiving sonidegib $200 \mathrm{mg}$ daily by investigator review

\begin{tabular}{|c|c|c|}
\hline & mRECIST criteria & ERIVANCE-like criteria \\
\hline laBCC, all & $n=66$ & $n=66$ \\
\hline ORR, \% (95\% Cl) & $71.2(58.7-81.7)$ & $74.2(62.0-84.2)$ \\
\hline CR, \% (95\% Cl) & $9.1(3.4-18.7)$ & $28.8(18.3-41.3)$ \\
\hline $\mathrm{PR}, \%$ & 62.1 & 45.5 \\
\hline $\mathrm{SD}, \%$ & 19.7 & 16.7 \\
\hline$P D, \%$ & 1.5 & 1.5 \\
\hline Unknown, \% & 7.6 & 7.6 \\
\hline laBCC, aggressive histology ${ }^{a}$ & $n=37$ & $n=37$ \\
\hline ORR, \% (95\% Cl) & $70.3(53.0-84.1)$ & $75.7(58.8-88.2)$ \\
\hline CR, \% (95\% Cl) & $8.1(1.7-21.9)$ & $29.7(15.9-47.0)$ \\
\hline $\mathrm{PR}, \%$ & 62.2 & 45.9 \\
\hline $\mathrm{SD}, \%$ & 21.6 & 16.2 \\
\hline$P D, \%$ & 0 & 0 \\
\hline Unknown, \% & 8.1 & 8.1 \\
\hline laBCC, nonaggressive histology ${ }^{b}$ & $n=29$ & $n=29$ \\
\hline ORR, \% (95\% Cl) & $72.4(52.8-87.3)$ & $72.4(52.8-87.3)$ \\
\hline CR, \% (95\% Cl) & $10.3(2.2-27.4)$ & $27.6(12.7-47.2)$ \\
\hline $\mathrm{PR}, \%$ & 62.1 & 44.8 \\
\hline $\mathrm{SD}, \%$ & 17.2 & 17.2 \\
\hline$P D, \%$ & 3.4 & 3.4 \\
\hline Unknown, \% & 6.9 & 6.9 \\
\hline
\end{tabular}

ancludes basosquamous, micronodular infiltrative, multifocal, and sclerosing histological subtypes

${ }^{b}$ Includes nodular and superficial histological subtypes

$C l$ confidence interval, $C R$ complete response, IaBCC locally advanced basal cell carcinoma, mRECIST modified RECIST, ORR overall response rate, $P D$ progressive disease, $P R$ partial response, RECIST Response Evaluation Criteria in Solid Tumors, SD stable disease 


\section{Discussion}

This preplanned sensitivity analysis of the BOLT study demonstrated greater tumor response rates when applying ERIVANCE-like criteria compared with mRECIST criteria for patients with laBCC receiving sonidegib $200 \mathrm{mg}$ QD. Overall, ORRs per central and investigator reviews were higher with ERIVANCE-like criteria vs mRECIST. In particular, the number of patients who achieved CR following treatment was substantially higher when ERIVANCE-like criteria were applied vs mRECIST-highlighting the differences in how tumor response and $\mathrm{CR}$ were defined between the two criteria sets. Additionally, tumor responses considered PR per mRECIST were defined as CR with ERIVANCE-like criteria, and patients with SD per mRECIST were considered either CR or PR when ERIVANCE-like criteria were applied. In particular, the most substantial difference between the two criteria sets is that when using the ERIVANCE-like criteria, patients with negative histology were considered $\mathrm{CR}$ regardless of their response based on MRI or color photography. In contrast, the mRECIST criteria required patients to have photographic assessment of CR, PR (scar/fibrosis only), SD (scar/fibrosis only), or NA and an MRI response of either CR or NA, in addition to negative histology for a patient to be considered to have achieved an overall composite response of CR.

These variations in how tumor response is assessed in patients with laBCC may stem from a lack of standardized terminology to define laBCC. Currently, the definition of laBCC can be grouped within the broader and vague terminology used to describe advanced $\mathrm{BBC}-$ which evolved for patients with $\mathrm{BCC}$ who were not surgical or radiotherapy candidates-and indicates patients who have a long disease history without treatment, were refractory to treatment, or had disease recurrence following treatment [6]. In addition, these patients may have widespread tissue destruction in the surrounding tumor area and curative resection with surgery or radiotherapy is no longer feasible or would result in significant deformity [6]. Moreover, common terms used to describe advanced BCC such as "locally advanced," "inoperable," and "considerable morbidity or deformity post-surgery" are subjective and highly dependent on the managing physician [4]. Consequently, the varying challenges in describing and managing advanced $B C C$ result in a generalized and ambiguous definition of laBCC.

Furthermore, unlike other solid tumors, BCC does not have a standard staging system due to the heterogenous nature and development of these tumors, which do not always follow the typical 3-step tumor-node-metastasis process (eg, tumor, nodal development, and distant metastases) [6]. As a result, progression-free survival (PFS) and overall survival results are less meaningful, and outcomes are not able to be accurately measured with RECIST criteria, as extensive tissue damage can occur without affecting survival in patients with laBCC [6]. Accordingly, in the ERIVANCE clinical studies evaluating safety and efficacy of vismodegib, a composite endpoint was designed to assess tumor response in patients with laBCC, since there was no standardized endpoint for laBCC $[24,26]$. Specifically, CR was defined as an absence of residual BCC in a biopsy sample, and PR was defined as a reduction of $\geq 30 \%$ in the radiographic or externally visible diameter of the tumor, or complete resolution of ulceration (if present at baseline) [26].PD was defined as an increase of $\geq 20 \%$ in radiographic or externally visible tumor dimension, development of new ulceration, or the presence of new lesions $[24,26]$. Similarly, in the BOLT study, a composite endpoint defined by mRECIST criteria evaluated tumor response in patients with laBCC to address the challenges and shortcomings of RECIST to accurately measure efficacy in these patients [22]. Consequently, differences in the specific endpoints and criteria used to define outcomes such as ORR, CR, PR, SD, and PD for the BOLT and ERIV ANCE studies result in efficacy outcomes that are difficult to compare for patients with laBCC. Hence, this preplanned sensitivity analysis applying ERIVANCE-like criteria to the BOLT outcomes was performed to generate more comparative results for sonidegib vs vismodegib. Subsequently, the results presented in this analysis demonstrate the differences used to evaluate tumor response and yielded higher response rates when using ERIVANCE-like criteria compared with the mRECIST criteria used in BOLT.

Limitations of this sensitivity analysis include the lack of PFS and time to tumor response data using ERIVANCE-like criteria in patients with laBCC. In addition, the efficacy of sonidegib in patients with recurrent disease following previous therapy with an $\mathrm{HHI}$ is unknown, since these patients were excluded from the BOLT study [21].

Overall, when ERIVANCE-like criteria were applied to patients with laBCC receiving sonidegib $200 \mathrm{mg}$ QD, tumor response rates were higher compared with the analyses using mRECIST criteria. These results continue to support the use of sonidegib to treat patients with laBCC. Since there are no current standardized assessment criteria for laBCC, practitioners should be cognizant of the specific differences between the two sets of criteria used to evaluate sonidegib and vismodegib when choosing a treatment regimen for their patients. Future studies on advanced BCC would benefit from a standardized definition of $\mathrm{laBCC}$ and uniform criteria to evaluate tumor response to better enable more accurate comparisons of efficacy across treatment options. 


\section{Abbreviations}

AE: adverse event; BCC: basal cell carcinoma; BOLT: Basal Cell Carcinoma Outcomes with LDE225 [sonidegib] Treatment; CR: complete response; DOR: duration of response; HHI: Hedgehog pathway inhibitor; laBCC: locally advanced BCC; mBCC: metastatic BCC; mRECIST: modified Response Evaluation Criteria in Solid Tumors; MRI: magnetic resonance imaging; NE: not estimable; ORR: objective response rate; PD: progressive disease; PFS: progression-free survival; PR: partial response; QD: once daily; RECIST: Response Evaluation Criteria in Solid Tumors; SD: stable disease; WHO: World Health Organization

\section{Supplementary Information}

The online version contains supplementary material available at https://doi. org/10.1186/s12885-021-08968-1.

\section{Additional file 1.}

\section{Acknowledgments}

This study was sponsored and funded by Novartis. Writing and editorial support for manuscript preparation were provided by Zehra Gundogan, VMD, of AlphaBioCom, LLC, and funded by Sun Pharmaceutical Industries, Inc., Princeton, NJ, USA. All authors met the International Council of Medical Journal Editors criteria and received neither honoraria nor payment for authorship.

\section{Authors' contributions}

$\mathrm{RG}, \mathrm{CR}, \mathrm{CL}, \mathrm{DS}, \mathrm{NS}, \mathrm{RA}, \mathrm{SM}$, and RD critically revised the manuscript. All authors had full access to the data, were involved in the revision of the manuscript for important intellectual content, gave final approval before submission, and agreed to be accountable for all aspects of the work, ensuring that questions related to the accuracy or integrity of any part of the work were appropriately investigated and resolved. The authors read and approved the final manuscript.

\section{Funding}

This work was supported by Sun Pharmaceutical Industries, Inc.

\section{Availability of data and materials}

The datasets created and analyzed during this study are available from the corresponding author upon reasonable request.

\section{Declarations}

\section{Ethics approval and consent to participate}

Written informed consent was obtained from all patients prior to the start of the study. The study protocol and all amendments were approved by the independent ethics committee or institutional review board for each center. This study was carried out in accordance with the ethical principles of the Declaration of Helsinki.

\section{Consent for publication}

Not applicable.

\section{Competing interests}

RG serves as consultant to Almirall; Amgen; Bristol-Myers Squibb; Immunocore; Merck Serono; Merck Sharp \& Dohme; Novartis; Pfizer; Pierre Fabre; Roche; Sanofi Genzyme; Sun Pharmaceutical Industries, Inc.; and 4SC; has received travel grants and honoraria for lectures from Almirall; Amgen; Bayer; Bristol-Myers Squibb; Merck Serono; Merck Sharp \& Dohme; Novartis; Pierre Fabre; Roche; and Sun Pharmaceutical Industries, Inc.; and has received research funding from Amgen; Johnson \& Johnson; Merck Serono; Novartis; and Sun Pharmaceutical Industries, Inc. CR has received consulting fees from Amgen, Bristol-Myers Squibb, Merck Sharp \& Dohme, Novartis, Pierre Fabre, Roche, and Sanofi. CL has acted as a speaker for, served on an advisory board for, and received honoraria from Bristol-Myers Squibb, Roche, Novartis, and Merck Sharp \& Dohme. DS has acted as a speaker for, served on an advisory board for, received research funding from, and/or received honoraria from 4SC Discovery, Agenus, Amgen, Array BioPharma, AstraZeneca, BristolMyers Squibb, Grünenthal Group, Immunocore, Incyte, LEO Pharma, Merck
Serono, Merck Sharp \& Dohme, Mologen, Novartis, Pfizer, Philogen, Pierre Fabre, Regeneron Pharmaceuticals, Roche, Sanofi, and Sysmex. NS, RA, and SM are employees of Sun Pharmaceutical Industries, Inc. RD has served on advisory boards and as a consultant for Amgen; Bristol-Myers Squibb; Catalym; Merck Sharpe and Dohme; Novartis Pharmaceutical Corporation; Pierre Fabre; Roche; Sanofi; Second Genome; Sun Pharmaceutical Industries, Inc.; and Takeda.

\section{Author details}

${ }^{1}$ Department Dermatology, Johannes Wesling Hospital Minden, Ruhr-University Bochum, Hans-Nolte-Str. 1, 32429 Minden, Germany. ${ }^{2}$ Department of Dermatology, Institut Gustave Roussy and Paris-Saclay University, Villejuif, France. ${ }^{3}$ Department of Dermatology, University Medical Center Mainz, Mainz, Germany. ${ }^{4}$ Dermatology Clinic, University Hospital, Essen, Germany. ${ }^{5}$ German Cancer Consortium, Heidelberg, Germany. ${ }^{6}$ Medical Affairs Oncology, Sun Pharmaceutical Industries, Inc., Princeton, NJ, USA. ${ }^{7}$ Sun Pharmaceutical Industries, (Europe) B.V., Hoofddorp, North Holland, Netherlands. ${ }^{8}$ Skin Cancer Center University Hospital, Zürich, Switzerland.

Received: 7 May 2021 Accepted: 20 October 2021

Published online: 19 November 2021

\section{References}

1. Bakshi A, Chaudhary SC, Rana M, Elmets CA, Athar M. Basal cell carcinoma pathogenesis and therapy involving hedgehog signaling and beyond. Mol Carcinog. 2017;56(12):2543-57. https://doi.org/10.1002/mc.22690

2. Marzuka AG, Book SE. Basal cell carcinoma: pathogenesis, epidemiology, clinical features, diagnosis, histopathology, and management. Yale J Biol Med. 2015;88(2):167-79.

3. Tay EY, Teoh YL, Yeo MS. Hedgehog pathway inhibitors and their utility in basal cell carcinoma: a comprehensive review of current evidence. Dermatol Ther (Heidelb). 2019;9(1):33-49. https://doi.org/10.1007/s13555-018-0277-7

4. Kim JYS, Kozlow JH, Mittal B, Moyer J, Olenecki T, Rodgers P. Guidelines of care for the management of cutaneous squamous cell carcinoma. J Am Acad Dermatol. 2018;78(3):560-78. https://doi.org/10.1016/j.jaad.2017.10.007

5. Migden M, Farberg AS, Dummer R, Squittieri N, Hanke CW. A review of hedgehog inhibitors Sonidegib and Vismodegib for treatment of advanced basal cell carcinoma. J Drugs Dermatol. 2021;20(2):156-65. https://doi.org/1 0.36849/JDD.5657

6. Peris K, Fargnoli MC, Garbe C, Kaufmann R, Bastholt L, Seguin NB, et al. Diagnosis and treatment of basal cell carcinoma: European consensusbased interdisciplinary guidelines. Eur J Cancer. 2019;118:10-34. https://doi. org/10.1016/j.ejca.2019.06.003

7. Lear JT, Corner C, Dziewulski P, Fife K, Ross GL, Varma S, et al. Challenges and new horizons in the management of advanced basal cell carcinoma: a UK perspective. Br J Cancer. 2014;111(8):1476-81. https://doi.org/10.1038/ bjc.2014.270

8. Dreier J, Cheng PF, Bogdan Alleman I, Gugger A, Hafner J, Tschopp A, et al. Basal cell carcinomas in a tertiary referral Centre: a systematic analysis. $\mathrm{Br} J$ Dermatol. 2014;171(5):1066-72. https://doi.org/10.1111/bjd.13217

9. Telfer NR, Colver GB, Morton CA. Guidelines for the management of basal cell carcinoma. Br J Dermatol. 2008;159(1):35-48. https://doi.org/10.1111/ j.1365-2133.2008.08666.x

10. Epstein EH. Basal cell carcinomas: attack of the hedgehog. Nat Rev Cancer. 2008;8(10):743-54. https://doi.org/10.1038/nrc2503.

11. Odomzo (sonidegib capsules). Full Prescribing Information. Sun Pharmaceutical Industries, Inc., Cranbury, NJ, USA. https://www.accessdata. fda.gov/drugsatfda_docs/label/2017/205266s004lbl.pdf. Accessed 1 May 2021.

12. Erivedge (vismodegib capsules). Full prescribing information. Genentech, San Francisco, CA, USA. https://www.accessdata.fda.gov/drugsatfda_docs/la bel/2017/203388s011lbl.pdf. Accessed 1 May, 2021.

13. European Medicines Agency. Summary of Product Characteristics, WC500188762. https://www.ema.europa.eu/en/documents/product-informa tion/odomzo-epar-product-information_en.pdf. Accessed 1 May 2021.

14. Swissmedic, Authorization Number 65065, 2015. https://www.swissmedic. ch/swissmedic/en/home/humanarzneimittel/authorisations/new-medicines/ odomzo--200mg--kapseln--sonidegibum-.html. Accessed 1 May 2021.

15. Australian Government Department of Health, ARTG 292262. https://www. tga.gov.au/sites/default/files/auspar-odomzo-191127.pdf. Accessed 1 May 2021. 
16. Australian Government Department of Health, ARTG 130429. https://www. ebs.tga.gov.au/ebs/picmi/picmirepository.nsf/pdf?OpenAgent\&id=CP-2013Pl-01667-1\&d=20211111172310101. Accessed 1May 2021.

17. DHPC - Erivedge (Vismodegib). Swissmedic 2016. https://www. swissmedicinfo.ch/?Lang=EN\#section1. Accessed 1 May 2021.

18. European Medicines Agency. Summary of Product Characteristics, EMEA/H/ C/002602. https://www.ema.europa.eu/en/documents/product-information/ erivedge-epar-product-information_en.pdf. Accessed 1 May 2021.

19. Dummer R, Guminksi A, Gutzmer R, Lear JT, Lewis KD, Chang ALS, et al. Long-term efficacy and safety of sonidegib in patients with advanced basal cell carcinoma: 42-month analysis of the phase II randomized, double-blind BOLT study. Br J Dermatol. 2020;182(6):1369-78. https://doi.org/10.1111/ bjd. 18552

20. Dummer R, Guminski A, Gutzmer R, Dirix L, Lewis KD, Combemale P, et al. The 12-month analysis from Basal Cell Carcinoma Outcomes with LDE225 Treatment (BOLT): a phase II, randomized, double-blind study of sonidegib in patients with advanced basal cell carcinoma. J Am Acad Dermatol. 2016; 75(1):113-125.e115.

21. Lear JT, Migden MR, Lewis KD, Chang ALS, Guminski A, Gutzmer R, et al. Long-term efficacy and safety of sonidegib in patients with locally advanced and metastatic basal cell carcinoma: 30-month analysis of the randomized phase 2 BOLT study. J Eur Acad Dermatol Venereol. 2018;32(3): 372-81. https://doi.org/10.1111/jdv.14542

22. Migden MR, Guminski A, Gutzmer R, Dirix L, Lewis KD, Combemale P, et al. Treatment with two different doses of sonidegib in patients with locally advanced or metastatic basal cell carcinoma (BOLT): a multicentre, randomised, double-blind phase 2 trial. Lancet Oncol. 2015;16(6):716-28. https://doi.org/10.1016/S1470-2045(15)70100-2

23. Eisenhauer EA, Therasse P, Bogaerts J, Schwartz LH, Sargent D, Ford R, et al. New response evaluation criteria in solid tumours: revised RECIST guideline (version 1.1). Eur J Cancer. 2009;45(2):228-47. https://doi.org/10.1016/j.ejca.2 008.10 .026

24. Sekulic A, Migden MR, Basset-Seguin N, Garbe C, Gesierich A, Lao CD, et al. Long-term safety and efficacy of vismodegib in patients with advanced basal cell carcinoma: final update of the pivotal ERIVANCE BCC study. BMC Cancer. 2017;17(1):332. https://doi.org/10.1186/s12885-017-3286-5

25. World Health Organization: WHO handbook for reporting results of cancer treatment: World Health Organization; 1979.

26. Sekulic A, Migden MR, Oro AE, Dirix L, Lewis KD, Hainsworth JD, et al. Efficacy and safety of vismodegib in advanced basal-cell carcinoma. N Engl J Med. 2012;366(23):2171-79. https://doi.org/10.1056/NEJMoa1113713

\section{Publisher's Note}

Springer Nature remains neutral with regard to jurisdictional claims in published maps and institutional affiliations.

Ready to submit your research? Choose BMC and benefit from:

- fast, convenient online submission

- thorough peer review by experienced researchers in your field

- rapid publication on acceptance

- support for research data, including large and complex data types

- gold Open Access which fosters wider collaboration and increased citations

- maximum visibility for your research: over $100 \mathrm{M}$ website views per year

At BMC, research is always in progress.

Learn more biomedcentral.com/submissions 